\title{
Paralelismo lingüístico
}

\author{
Maria Marta Pereira Scherre \\ Universidade Federal do Rio de Janeiro/ \\ Universidade de Brasília/CNPq
}

\section{Abstract}

Linguistic parallelism has been widely discussed in variationist literature as an independent variable, often in the form of repetition of the same variant of the dependent variable, in many linguistic phenomena and in a vast number of languages. In this paper, I discuss three main aspects of parallelism: (i) whether it can be interpreted within the functional theoretical framework; (ii) the existence of underlying functional principles; and (iii) whether it can be accounted for by a single principle. In my discussion, I will present results for three linguistic phenomena that are affected by linguistic parallelism on the discourse, clausal, syntagmatic, and word levels in Brazilian Portuguese. I will then discuss a large body of research in which this constraint has been analyzed. I conclude that the study of linguistic parallelism shows that the study of language use and structure can be better accounted for through variationist theory, functionalism, and discourse analysis working together. 


\section{1- INTRODUÇÃO'}

A própria repetição das variantes de uma mesma variável dependente no discurso tem se evidenciado como uma restrição importante na análise de fenômenos variáveis de todos os subsistemas lingüísticos em diversas línguas. Esta restrição ou variável independente ocorre entre as cláusulas (plano discursivo), no interior da oração (plano oracional), no interior do sintagma (plano sintagmático), e entre palavras e no interior da palavra (plano da palavra). Recebendo denominações diferenciadas dentro da literatura variacionista, ela é hoje bastante conhecida como paralelismo lingüistico, denominação assumida neste texto. Embora esta variável tenha um efeito uniforme e geral - candidata a universal de uso e processamento lingüístico (cf. Scherre \& Naro, 1991) -, sua interpretação ainda tem sido bastante diversificada.

Então, pelo menos três questões fundamentais se colocam em discussão aqui:

1) A interpretação da variável paralelismo é de base funcionalista?

2) Caso seja, existe algum princípio funcionalista estabelecido que a ela subjaz?

3) O paralelismo que perpassa pelos diferentes subsistemas lingüísticos e pelos diversos planos lingüísticos pode ser interpretado por meio de um só princípio?

Importante se faz adiantar que as condições de distintividade nos termos de Kiparsky (1972), o princípio da economia nos termos de Haiman (1983) e de Du Bois (1985) ou o princípio da quantidade nos termos de Givón (1991) - estabelecidos para dar conta da tendência de eliminar ou codificar menos o que é mais previsível e de reter ou codificar mais o que é menos previsível - não dão conta 
da interpretação do efeito do paralelismo, tendo em vista que, neste caso, repetem-se variantes explícitas formalmente semelhantes mais codificação explícita leva a mais codificação explícita -, e repetem-se também variantes zero - menos codificação explícita leva a menos codificação explícita.

Na concordância de número no português do Brasil, o funcionamento do paralelismo é particularmente interessante, porque, em algumas circunstâncias, tende-se a repetir variantes explícitas de plural - codificando mais o que é mais previsível-e tende-se a repetir variantes zero de plural - codificando menos o que é menos previsível. Todavia, na interpretação de fenômenos variáveis de concordância explícita - fenômenos de codificação redundante -, evocou-se sistematicamente (e ainda evoca-se) o princípio da economia, associado pelo senso comum à lei do menor esforço, com o objetivo de dar conta da variante zero de plural - interpretada como falta de concordância.

Até certa data, buscando efeito de fatores de natureza informacional em suas análises - fatores funcionais -, muitos pesquisadores deparam-se com o efeito do paralelismo - visto como contrafuncional -, e relatam-no com certa perplexidade. As palavras de Poplack (1980) sobre a noção de plural no espanhol de Porto Rico; as de Lefebvre (1981) sobre a variação de plural no quechua de Cuzco, e as de Omena (1978) sobre as formas variantes do pronome de terceira pessoa em função acusativa no português do Brasil ilustram este fato:

“(..) presença de uma marca plural precedente ao dado favorece a retenção de marca no dado, enquanto ausência de uma marca precedente favorece cancelamento (...) (...) O contexto mais favorável para o cancelamento da marca é precisamente quando duas marcas precedentes já foram canceladas. (...) (...) de forma geral, vimos que fatores funcionais [informacionais] afetam o cancelamento da marca menos do que qualquer outro grupo de fatores estudado, com exceção do acento seguinte, um resultado que não éprontamente interpretável. (Poplack, 1980, p.63; 64; 66) (grifos meus). 
Os demais fatores, entretanto, não confirmam tão bem a hipótese funcionalista. Isto envolve casos nos quais não há informação de plural no SN sujeito (...) e casos em que há informação de plural no sujeito (...). Uma hipótese funcionalista preveria que a primeira categoria favoreceria flexão de plural no verbo para preservar a informação no nível da oração, enquanto a segunda categoria permitiria menos flexão no verbo uma vez que a pluralidade já estava marcada no sujeito. Os resultados mostram o contrário. (Lefebvre, 1981, p.81-2) (grifos meus)

(...) Outro fator a inibir a aplicação da regra foi a referência reiterada ao elemento que constituía o assunto do discurso. A idéia de que o falante tenderia a apagar o pronome objeto mais facilmente em seguida ao apagamento de um substantivo, do que ao aparecimento de um pronome pessoal que já seria uma cópia, mostrou-se, na prática, irrelevante. Pensávamos em uma regularidade na seqüência dos itens lexicais, tendo em vista seu conteúdo semântico (...). A lógica lingüística revelou-se outra. Nossos falantes tendem mais a usar o pronome objeto, quando antes já aparece uma seqüência de nomes e/ou pronomes". (Omena, 1978, p.100) (grifos meus).

Embora direta ou indiretamente os pesquisadores se reportem ao efeito da variável paralelismo, todos eles apresentam influência de variáveis de natureza diversa, de natureza informacional e nãoinformacional, configurando a existência de motivações em competição, que, segundo Du Bois (1985), constitui a situação natural de qualquer língua natural.

\section{2 - RESULTADOS DA VARIÁVEL PARALELISMO EM QUATRO ESTUDOS SOBRE O PORTUGUÊS DO BRASIL²}

Para exemplificar o efeito do paralelismo em pesquisas sobre o português do Brasil, vou me reportar a quatro estudos bem distintos, dos quais participaram pesquisadores do PEUL: variação tempo-modo em orações condicionais (Gryner, 1990); concordância de número (Scherre, 1988; 1991; 1997; Scherre \& Naro, 1991; Naro \& Scherre, 1996); presença/ausência de preposição de em fronteiras oracionais (Mollica, 1989; 1991; 1995); alternância indicativo/ subjuntivo em estruturas imperativas (Scherre et alii, 1997). 


\section{A variação tempo-modo nas condicionais: plano discursivo}

O estudo de Gryner aborda a alternância tempo-modo e conexão em orações condicionais potenciais, analisando três possíveis alternativas: futuro do subjuntivo (Se vocêcorrer, o bicho pega), presente do indicativo (Se vocêcorre, o bicho pega) e gerúndio (Correndo, o bicho pega). Trata-se de um estudo semânticopragmático, que incorpora avanços do tratamento quantitativo para formas que têm a ver com diferenças semântico-discursivas, analisadas por meio de variáveis independentes. Na Tabela 1, observa-se o efeito regular e polarizado do paralelismo no plano discursivo na alternância destas três formas.

\section{Tabela 1}

\begin{tabular}{|c|c|c|c|c|c|c|}
\hline \multirow{2}{*}{$\begin{array}{c}\text { VARIANTES } \longrightarrow \\
\text { FATORES }\end{array}$} & \multicolumn{2}{|c|}{ Futuro do subjuntivo } & \multicolumn{2}{|c|}{ Presente do indicativo } & \multicolumn{2}{|l|}{ Gerúndio } \\
\hline & Freqüência & $\mathrm{PR}^{10}$ & Freqüência & PR & Freqüência & PR \\
\hline Estrutura paralela & $282 / 341=83 \%$ & $\mathbf{0 , 8 1}$ & $168 / 282=60 \%$ & $\mathbf{0 , 8 1}$ & $72 / 97=74 \%$ & 0,89 \\
\hline Estrutura não paralela & $106 / 643=17 \%$ & 0,22 & $47 / 702=7 \%$ & 0,20 & $47 / 887=57 \%$ & 0,19 \\
\hline Estrutura inicial & $756 / 1805=52 \%$ & 0,44 & $397 / 1805=22 \%$ & 0,49 & $260 / 1805=14 \%$ & 0,35 \\
\hline Total de dados & $1144 / 1984=58 \%$ & & $612 / 1984=31 \%$ & & $379 / 1984=19 \%$ & \\
\hline
\end{tabular}

Para as três variantes, evidencia-se a tendência ao aparecimento de estruturas paralelas: futuro do subjuntivo tende a provocar futuro do subjuntivo; presente do indicativo tende a provocar presente do indicativo e gerúndio tende a provocar gerúndio. As estruturas que iniciam as séries evidenciam efeito intermediário e indiferente na escolha das variantes.

\section{O (de)queísmo: plano discursivo}

O estudo de Mollica envolve a análise da presença/ausência da preposição de em contextos queístas (onde a preposição de deveria ocorrer mas às vezes não ocorre - ela nãogosta (o) que 
interrompam a aula para pedir explicações) e em contextos dequeístas (onde a preposição de não deveria ocorrer mas às vezes ocorre - eu acreditode que deve ter). Trata-se de estudo sintático, envolvendo a presença ou ausência da preposição de em fronteiras sentenciais introduzidas pelo complementizador que. Na Tabela 2, encontram-se os resultados do efeito do paralelismo em relação à presença da preposição de em ambientes queístas e dequeístas. Neste fenômeno, observa-se que, enquanto preposição precedente de favorece preposição de subseqüente, a ausência de material fônico de a desfavorece. A presença de outros des não preposicionais tem comportamento indiferente em relação ao fenômeno analisado.

Tabela 2

\begin{tabular}{|l|c|c|}
\hline \multicolumn{3}{|c|}{$\begin{array}{c}\text { Influência do paralelismo discursivo sobre a presença de de na variação } \\
\text { (de)queísta em português (Mollica, 1991) }\end{array}$} \\
\hline FATORES & Freqüência & Peso relativo \\
\hline Presença da preposição de & $17 / 34=50 \%$ & $\mathbf{0 , 6 4}$ \\
Ausência de material fônico de & $54 / 464=12 \%$ & $\mathbf{0 , 3 7}$ \\
Presença de de não-preposicional & $104 / 438=24 \%$ & $\mathbf{0 , 4 7}$ \\
\hline Total de dados & $175 / 936=19 \%$ & \\
\hline
\end{tabular}

\section{A concordância de número: plano discursivo, oracional e sintagmático}

O estudo de Scherre e de Scherre \& Naro focaliza três fenômenos de concordância de número no português do Brasil: entre os elementos do sintagma nominal (SN), na relação verbo/sujeito e nos predicativos e particípios passivos. Este estudo analisa variantes que fazem parte da morfossintaxe, envolvendo unidades que trazem uma informação semântica - a noção de pluralidade - expressa por duas variantes: variante explícita de plural e variante zero de plural. No plano discursivo, a análise evidenciou o efeito do paralelismo sobre os três fenômenos analisados; no plano oracional, sobre a concordância verbal e sobre a concordância nos predicativos/particípios 
passivos; e, no plano sintagmático, sobre a concordância entre os elementos do SN.

\section{Plano discursivo}

Os resultados da Tabela 3 indicam que SN precedente idêntico ou do mesmo campo semântico - com todas as variantes explícitas favorece SN subseqüente igualmente marcado, enquanto SN que apresenta pelo menos uma variante zero favorece SN subseqüente com pelo menos uma variante zero. Verbo precedente - referente ao mesmo sujeito ou a sujeito do mesmo campo semântico - com variante explícita favorece verbo subseqüente igualmente marcado, enquanto verbo com variante zero favorece verbo com variante zero. Predicativo precedente - idêntico ou referente ao mesmo sujeito - com variante explícita favorece predicativo subseqüente com variante explícita, enquanto predicativo com variante zero favorece predicativo subseqüente com variante zero.

\section{Tabela 3}

Influência do paralelismo discursivo sobre a presença da variante explícita de plural em português (Scherre \& Naro, 1991; Naro \& Scherre, 1996)

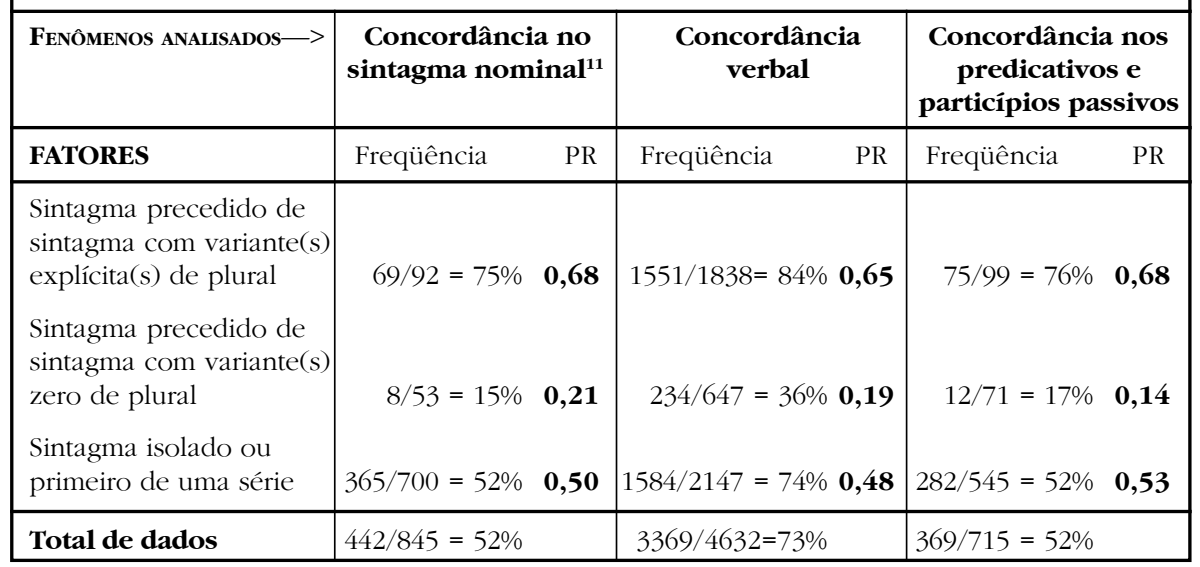


Os resultados evidenciam a mesma tendência nos três fenômenos, com magnitude semelhante. As estruturas isoladas ou primeiras de uma série exibem resultados intermediários, próximos ao peso de influência neutra.

\section{Plano oracional}

$\mathrm{Na}$ Tabela 4, observa-se o efeito das marcas do sujeito sobre o verbo e sobre os predicativos e particípios passivos: variante explícita no(s) último(s) elemento(s) do sujeito favorece variante explícita nos verbos (os alunos aceitaram isso/as coisas tão caras) e nos predicativos e particípios passivos correspondentes (as coisas tão caras); variante zero favorece variante zero (as pessoao não podeO/as coisao tá cara).

\section{Tabela 4}

\begin{tabular}{|c|c|c|c|c|}
\hline \multicolumn{5}{|c|}{$\begin{array}{l}\text { Influência do paralelismo oracional sobre a presença da variante explícita de plural na } \\
\text { concordância verbal e nos predicativos e particípios passivos: marcas do sujeito } \\
\text { (Scherre \& Naro, 1991) }\end{array}$} \\
\hline Fenômenos—> & \multicolumn{2}{|c|}{$\begin{array}{c}\text { Concordância no sintagma } \\
\text { verbal }\end{array}$} & \multicolumn{2}{|c|}{$\begin{array}{c}\text { Concordância nos predicativos } \\
\text { e particípios passivos }\end{array}$} \\
\hline FATORES & Freqüência & Peso relativo & Freqüência & Peso relativo \\
\hline $\begin{array}{l}\text { Variante explícita no(s) } \\
\text { último(s) elemento(s) } \\
\text { do sujeito } \\
\text { Variante zero no(s) } \\
\text { último(s) elemento(s) } \\
\text { do sujeito }\end{array}$ & $1755 / 2134=82 \%$ & 0,56 & $123 / 207=59 \%$ & 0,58 \\
\hline Percentagem global & $78 \%$ & & $51 \%$ & \\
\hline
\end{tabular}

Na Tabela 5, apresenta-se o efeito das marcas do verbo sobre os predicativos e particípios passivos: variante explícita no verbo favorece variante explícita nos predicativos (as coisastão caras) e variante zero favorece variante zero (as coisatá carao). 


\section{Tabela 5}

\begin{tabular}{|l|c|c|}
\hline \multicolumn{3}{|c|}{$\begin{array}{l}\text { Influência do paralelismo oracional sobre a presença da variante explícita de plural nos } \\
\text { predicativos e particípios passivos: marcas dos verbos precedentes (Scherre \& Naro, 1991) }\end{array}$} \\
\hline FATORES & Freqüência & Peso relativo \\
\hline Variante de plural explícita no verbo & $324 / 582=56 \%$ & $\mathbf{0 , 5 5}$ \\
Variante de plural zero no verbo & $11 / 81=14 \%$ & $\mathbf{0 , 1 8}$ \\
\hline Percentagem global & $51 \%$ \\
\hline
\end{tabular}

\section{Plano sintagmático}

Na Tabela 6, observa-se o efeito de marcas dentro do SN sobre marcas dentro do próprio SN, ou seja, mede-se o efeito das marcas precedentes sobre o elemento nominal analisado. Focalizo aqui os SNs de três ou mais elementos. Neste caso, variantes explícitas precedentes da mesma natureza tendem a favorecer variantes explícitas seguintes; variante(s) explícita(s) seguida(s) de zero(s) tende(m) a favorecer zero(s) seguinte(s). Então, um SN de três ou mais elementos com variantes explícitas em seus primeiros elementos (aquelas rendas / a pessoas todas terá mais possibilidade de exibir variante explícita no elemento da terceira e no da quarta posição (aquelas rendas todaS/aS pessoas toda iguaIS); inversamente, um SN de três ou quatro elementos com variante zero a partir do primeiro elemento (essaS carne $\boldsymbol{O}$ umas camisaO muito /dois risco0 / as pernao todaO ) terá mais possibilidade de exibir a variante zero no elemento

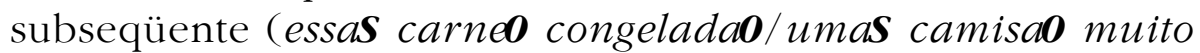
lindaO/dois riscoO verdeO/aS pernaO todaO marcadaO). Este segundo fator tem efeito quase categórico no sentido de desfavorecimento da variante explícita. Mistura de marcas precedentes ou a presença de marcas semelhantes não-adjacentes ( $d o \boldsymbol{O}$ meu $\boldsymbol{S}$ tios; dez senhoras lá sentada; oS meuS quatro filhos; aS criançaS todas da rua abandonadas, aquelas pessoas assim bem esquisitinha), por sua vez, apresenta efeito intermediário e, também, próximo ao ponto neutro. 


\section{Tabela 6}

\begin{tabular}{|c|c|c|}
\hline FATORES & Freqüência & Peso relativo \\
\hline $\begin{array}{l}\text { Duas ou mais marcas explícitas } \\
\text { imediatamente precedentes }\end{array}$ & $294 / 418=70 \%$ & 0,68 \\
\hline $\begin{array}{l}\text { Zero(s) precedente }(\mathrm{s}) \text { a partir da } \\
\text { primeira posição }\end{array}$ & $14 / 225=6 \%$ & 0,07 \\
\hline $\begin{array}{l}\text { Mistura de marcas com marca } \\
\text { explícita precedente ou marcas } \\
\text { semelhantes não-adjacentes }\end{array}$ & $235 / 442=53 \%$ & 0,48 \\
\hline Percentagem global & $=72 \%$ & \\
\hline
\end{tabular}

\section{A expressão do imperativo: plano da palavra}

O estudo de Scherre et alli (1997) diz respeito à expressão do modo imperativo por meio do indicativo (passa o braço na frente), do subjuntivo (passe para a folbinha 29) e do infinitivo (passar na secretaria para assinar a lista dos formandos), na língua falada e escrita. Para os objetivos no presente artigo, vou mencionar apenas resultados de língua falada, que envolvem as duas primeiras variantes.

Os resultados da Tabela 7 indicam que, se a vogal imediatamente precedente da forma verbal conjugada for mais aberta, favorece-se o uso do imperativo na forma indicativa, expressa pela vogal temática [a], uma vogal também aberta; se a vogal for menos aberta, favorece-se o uso do imperativo na forma subjuntiva, expressa pela vogal característica do modo subjuntivo [i], uma vogal fechada. Verifica-se, portanto, um processo de harmonização vocálica envolvendo um fenômeno morfossintático. Trata-se de mais uma manifestação do paralelismo lingüístico, de natureza fônica, estendido para o plano da palavra. ${ }^{3}$ 


\section{Tabela 7}

\begin{tabular}{|c|c|c|}
\hline \multicolumn{2}{|c|}{$\begin{array}{c}\text { Influência do paralelismo no plano da palavra sobre a forma indicativa nas orações imperativas } \\
\text { Natureza da vogal imediatamente precedente na forma verbal conjugada em verbos regulares } \\
\text { da primeira conjugação (Scherre et alii, 1997) }\end{array}$} \\
\hline FATORES E EXEMPLOS & Freqüência & Peso relativo \\
\hline [vogal mais aberta] & $82 / 88=93 \%$ & $\mathbf{0 , 6 4}$ \\
- fala/fale & $124 / 135=92 \%$ & $\mathbf{0 , 6 8}$ \\
- olha/olhe & $42 / 52=81 \%$ & $\mathbf{0 , 6 0}$ \\
- espera/espere & & $\mathbf{0 , 3 4}$ \\
[vogal menos aberta] & $17 / 22=77 \%$ & $\mathbf{0 , 3 7}$ \\
• manda/mande & $24 / 28=86 \%$ & $\mathbf{0 , 4 6}$ \\
- tenta/tente & $50 / 61=82 \%$ & $\mathbf{0 , 3 0}$ \\
- vira/vire & $46 / 63=73 \%$ & $\mathbf{0 , 2 3}$ \\
- usa/use & $43 / 64=67 \%$ & \\
\hline Total & $428 / 513=83 \%$ & \\
\hline
\end{tabular}

Para a presente discussão, a importância dos resultados obtidos pelos estudos dos fenômenos aqui sintetizados está exatamente na sua uniformidade: todos eles evidenciam uma tendência clara de formas semelhantes se agruparem, seja qual for o tipo e o plano do fenômeno analisado.

\section{3 - SOBRE A INTERPRETAÇÃO DO PARALELISMO}

A variável paralelismo tem recebido interpretações as mais diversas por parte dos pesquisadores variacionistas - uma verdadeira "babel" de interpretações -, que aqui buscamos sintetizar e sistematizar. Grande parte dos pesquisadores assumem explicitamente que esta variável tem um caráter contra-funcional. Direta ou indiretamente, as interpretações assumidas como não-funcionalistas restringem o sentido de funcional ao aspecto informacional, nos termos das condições de distintividade de Kiparsky (1972) ou do princípio da economia de Haiman (1984) e Du Bois (1985), ou do princípio da quantidade de Givón (1991), que estabelecem que a informação mais previsível é menos codificada. Esta visão nãofuncionalista é reiterada por Labov (1994), na reformulação de seu artigo The Overestimation of functionalism publicado em 1987, como se pode ver a seguir: 
"Na última metade do século um grupo de escolas e correntes lingüísticas têm trabalhado sob o rótulo de funcionalismo. Elas têm se orientado pelas noções de 'função', 'comunicação', e 'significado', de uma forma que pode ser resumida na seguinte colocação básica: (1) A função da linguagem consiste em o falante (ou redator) comunicar significado para o ouvinte (ou leitor).

(..) Em geral, discussões do efeito funcional se referem à necessidade de representar um estado de coisas com proposições que sejam capazes de distinguir entre afirmações que são verdadeiras e afirmações que não o são, junto com suas extensões de modo interrogativo, imperativo e outros modos. Além disso, estas discussões têm incluído várias formas de chamar a atenção para as partes das orações, como indicado através de termos tais como foco e não-foco, figura e fundo, topicalização. Mas estas discussões a respeito de efeitos funcionais normalmente não incluem a função de representar o estado emocional do falante, as relações sociais entre falante e ouvinte, a facilidade da fala e comunicação através da condensação, abreviação, ou meios mecânicos.

(....) De dez anos para cá, eu e outros pesquisadores que observamos a linguagem em uso temos sido bastante cépticos a respeito de argumentos que atribuem eficácia ao controle do significado sobre a língua e sobre a mudança lingüística. Afirma-se freqüentemente que os falantes levam em conta o estado informacional de seus ouvintes quando falam, e que, dada uma escolha entre duas alternativas, eles vão favorecer aquela que colocará seu significado de forma mais eficiente e mais efetiva. Mas, pelo que se segue, veremos que estudos quantitativos do uso da linguagem não confirmam este tipo de colocação.

Argumentos funcionalistas não são facilmente desencorajados. Comunicação e significado aparecem lá como elementos que são inerentemente bons; um mecanismo lingüístico é considerado melhor se ele comunica mais informação, e pior se não o faz. Eu me considero bastante céptico a respeito do que é inerentemente bom.

(...) Não estou afirmando que argumentos funcionais são ilusões. Mas veremos que a necessidade de preservar a informação é relativamente fraca, e pode ser suplantada por uma variedade de outros fatores.

(...) [Em síntese, todos] os resultados [apresentados] mostram uma extraordinária consistência. Dada uma variação fonológica ou 
morfológica, a hipótese funcionalista prediz uma tendência para os falantes escolherem uma ou outra variante de forma que a informação seja preservada. A maioria dos resultados citados aqui mostram o oposto: na cadeia da fala, uma variante ou outra é escolhida sem olhar a maximização da informação. Pelo contrário, os principais efeitos que determinam tais escolhas são mecânicos: condicionamentos fonéticos e simples repetição da estrutura precedente". (Labov, 1994 p.548, 549, 550; 568)

Pela leitura que fiz da relação entre variacionistas e funcionalistas, os pesquisadores que consideraram a variável paralelismo em suas pesquisas podem ser agrupados da seguinte forma: (I) uns partilham da visão mais restrita de funcionalismo nos termos explicitados por Labov: Poplack (1980); Weiner \& Labov (1983); Lefebvre (1981); Naro (1981a); Guy (1981); Scherre (1988); Scherre \& Naro (1991; 1992; 1993); (II) outros adotam uma visão funcionalista mais ampla: Schiffrin (1981); Lira (1982); Braga (1986); Gryner (1990); Mollica (1989;1991;1995); (III) um terceiro grupo busca explicações funcionais num sentido amplo sem explicitar suas hipóteses funcionalistas: Emmerich (1977; 1984); Sankoff \& Laberge (1978); Macedo (1981); Omena (1978; 1996).

Todavia, com relação à forma de interpretação desta variável, os pesquisadores acima se reorganizam e, às vezes, não se agrupam tão claramente.

Poplack (1980, p.65) atribui a força do paralelismo à lei do menor esforço assim formulada por Martinet (1962, p.55):

"Concordância é redundância, e ao contrário do que seria esperado, redundância resulta, como uma regra, do menor esforço: as pessoas não se importam em repetir se o esforço mental é por isto reduzido."

Weiner e Labov (1983, p.56) consideram que o paralelismo evidencia uma tendência mecânica para preservar a estrutura paralela, com influência indubitável de um fator estilístico, descartando a existência de uma tendência cognitivamente determinada para se continuar falando do mesmo assunto. Em 1994, Labov mantém a mesma postura em relação ao caráter mecânico desta variável, e 
a utiliza como argumento para projetar um modelo da mudança lingüística lenta de base não-funcionalista - no seu sentido mais restrito, o de preservação da informação (cf., especialmente, p.548).

Schffrin (1981, p.55-6) também afirma que a manutenção de formas semelhantes no discurso "parece ser uma tendência geral de formas gramaticais particulares ocorrerem juntas". Embora admita que a mudança de forma possa ter uma função discursiva, considera que a sua manutenção não tem "efeito comparável", podendo "resultar de uma restrição mais mecânica".

Scherre (1988, p.301; 385-6) também considera que o efeito do paralelismo deve ser interpretado como uma "tendência geral de formas gramaticais particulares ocorrerem juntas", ponderando que uma questão maior de processamento deve envolver este tipo de variável. Afirma que a "sua forma de atuar cria uma harmonia discursiva formal, tornando o discurso mais coeso". Continuando seu raciocínio, coloca que

"(...) em verdade, a forma de atuar da variável Paralelismo formal mostra que os falantes são compelidos a usar formas semelhantes por algum princípio mental associativo, que pode estar ligado a uma das formas da mente humana operar, refletido no comportamento humano em geral."

Guy (1981, p.252) afirma que o fato de a concordância nominal e verbal covariarem

"seria um reflexo do grau de auto-monitoração, um efeito "estilístico" mais sutil do que o que estamos sendo capazes de discriminar com a nossa medida de estilo de fala relativamente crua, medida com base no assunto do estilo da fala."

Omena (1978, p.100) considera que “(...) parece influenciar aí o mecanismo enfático da repetição. (...)”. Sankoff \& Laberge (1978, p.122) se perguntam se a "restrição seqüencial é uma forma de coerência textual (...) ou se ela apenas reflete homogeneidade estilística dentro de passagens curtas de conversação”. Lefebvre 
(1981, p.81-2), secundada por Lira (1982, p.150), sugere que "parece haver um fenômeno de concordância superficial (...)".

Braga (1986, p.412) afirma que todas as construções de tópico (CTs) de objeto direto analisadas, mesmo as que exercem funções não definidas, revelam uma característica comum:

"(...) a retomada de um item já evocado anteriormente ou a menção a constituintes de conceitos também já referidos. Esta volta ao texto anterior parece ser a macro-função das CTs (...). Esta característica das CTs aponta para e, enquanto tal, caracteriza-se como um dos mecanismos coesivos de que dispõe o falante."

Naro (1981a, p.355) observa que a preferência de sujeitos vazios com verbos fortes sem concordância significa que falantes evidenciam uma grande inclinação para evitar conflito superficial entre a presença de sujeito e o verbo forte sem concordância. Assim, o princípio é "elimine conflito".

Macedo (1981, p.165-6) afirma que fatores deste tipo "podem ser generalizados como fatores que, de um modo ou de outro, atuam sobre a memória em níveis bastante superficiais da sintaxe". Emmerich (1977, p.399; 396-7; 1984, p.222-3) coloca que "a variável em questão leva a admitir o funcionamento de condicionamentos psicolingüísticos" que funcionam nos processos de aquisição da linguagem, seja de primeira ou de segunda língua, denominando-a de "traço propulsor ou gatilho". Mollica (1990, p.106-7), por sua vez, também considera que a sua influência seja de "caráter psicolingüístico".

Gryner (1990, p183-4; 186-7; 209; 215) discute a diversidade de interpretação atribuída a esta variável, polemizando a discussão:

\footnotetext{
“(...) as variantes são elementos significativos, o que torna improvável que seu uso repetido seja decorrente de natureza meramente formal (...);

(...) a identificação de uma função pragmático-discursiva e, portanto, de livre escolha do locutor não é facilmente associada à imagem de um gatilho de revólver que propulsiona automaticamente a bala. Isto
} 
porque se omite precisamente quem aciona o gatilho e por que $\mathrm{o}$ faz. (...) Assim, parece confirmar-se a hipótese de que a repetição de formas é um fator de coerência textual (...);

(...) afirmamos anteriormente que a manutenção ou mudança de variantes está relacionada a propósitos discursivos específicos. Assim a) a manutenção de variantes em seqüência (...) expressaria uma intensificação e/ou equivalência - isto é, a manutenção de 'atitude' b) a mudança de variantes em seqüência (...) expressaria uma mudança no plano ou foco - isto é, uma mudança de 'atitude' (...) (...) De fato, se a mudança de formas expressa a mudança de cenário, foco ou perspectiva, parece razoável supor que a recorrência das formas expressa a sua manutenção. (...)".

Mas, à exceção de Poplack (1980), que faz referência à lei do menor esforço como formulada por Martinet no texto de 1962, não encontrei nos demais estudos referência explícita a nenhum princípio funcionalista estabelecido. Observando que nenhum dos princípios funcionalistas conhecidos dá conta do paralelismo, Scherre (1988, p.419) arrola-os da seguinte forma:

1) princípio da iconicidade ou motivação icônica (isomorfismo entre forma/significado) (cf. Haiman, 1983; Du Bois, 1985);

2) princípio da economia ou motivação econômica (tendência a eliminar ou a codificar menos o que é previsível) (cf. Haiman, 1983; Du Bois, 1985);

3) princípio do fluxo de informação preferido (pressão discursiva para se codificar a informação nova) (cf. Du Bois, 1985);

4) princípio da topicidade (pressão discursiva para se codificar tópico/agente) (cf. Du Bois, 1984);

5) princípio da natureza comunicativa periférica da oração VS (princípio da baixa tensão comunicativa: tendência para colocar à direita a informação menos central) (cf. Naro \& Votre, 1986, p.464-6).

Embora não seja possível estabelecer relação entre o efeito do paralelismo e os princípios arrolados acima, quase todas as 
interpretações vão encontrar, de uma forma ou de outra, respaldo nas idéias de Tannen (1989. cf., especialmente, p.1-4;36-97) expostas em Talking voices, obra inserida na abordagem lingüística denominada Análise do Discurso. ${ }^{4}$ Segundo Tannen (1989, p.3-97), o mecanismo da repetição - sistematicamente estudado por diferentes pesquisadores - é central não só na criação de um discurso particular, mas na criação do discurso em si mesmo, ou seja, na criação da língua. Considera que, no processo de conversação, os diversos propósitos para os quais a repetição trabalha podem ser resumidos pelas categorias da produção, da compreensão, da conexão e da interação. Portanto, a repetição:

1) permite ao falante produzir linguagem com mais eficiência, menos energia, mais fluência e de forma automática;

2) facilita a compreensão por produzir um discurso com menos densidade semântica, ou seja, com mais redundância;

3) evidencia como novos enunciados são conectados ao discurso precedente, e como as idéias apresentadas no discurso se interrelacionam.

"Mas este é somente o meio mais claro e direto por meio do qual a repetição permite ao falante dar forma à substância. (...) De uma forma mais sutil e intensa, a repetição evidencia uma atitude do falante, mostrando como esta atitude contribui para o significado do discurso." (...) Ela é avaliativa, [no sentido laboviano do termo, segundo Tannen]: contribui para a determinação do ponto. Aqui se encaixa a função da repetição que é normalmente considerada como ênfase, bem como uma série de outras avaliações de proposições, ou relações entre proposições." (p.50);

4) funciona no nível interacional do discurso, ligando objetivos sociais ou simplesmente conduzindo o assunto da conversa

“(...). Em outras palavras, a repetição liga não somente partes do discurso entre si, mas une os participantes do discurso, integrando os falantes em conversas e em relações" (p.51-52),

ao lado

"das funções da repetição discutidas sob os rótulos de produção, compreensão, e conexão, [que] conduzem à construção do significado na conversação." (p.51) 
Enfim, a conjugação destas quatro funções - facilitando a produção, a compreensão, a conexão e a interação - resulta, segundo ela, em uma função mais abrangente - uma meta-função -, a da construção da coerência e do envolvimento interpessoal. (p.3; 48; 52).

Em busca de uma correlação entre as interpretações variacionistas e a sistematização apresentada por Tannen, considero que:

1) facilidade de processamento associada à lei do menor esforço, tendência à repetição mecânica de formas semelhantes, funcionamento da memória imediata, aspectos psicolingüísticos de processamento, auto-monitoração e fatores estilísticos se relacionam à produção;

2) processamento não-mecânico de formas gramaticais semelhantes associado a uma das possíveis formas da mente humana operar, a de aproximar formas pelas suas semelhanças, criando coesão discursiva, se liga à produção e à cone$x \widetilde{a} O$;

3) manifestação ou escolha de funções pragmático-discursivas; manifestação de propósitos discursivos específicos coerência textual, mecanismos coesivos, ênfase, estabelecimento de foreground, mudança e manutenção de atitude, e concordância formal superficial se associam à conexão;

4) efeito gatilho se relaciona à interação.

Todas as interpretações têm em comum o fato de levarem em consideração aspectos da repetição que, segundo Tannen, contribuem para a construção do significado do discurso e, em última análise, para a construção da coerência discursiva e do envolvimento interpessoal. Portanto, todas as interpretações são discursivas e, num sentido amplo, inegavelmente funcionalistas. Portanto, considerar ou não a variável paralelismo como funcionalista ou não-funcionalista vai depender da amplitude do sentido da palavra funcionalista.

Mesmo sem aprofundar esta discussão no presente momento, gostaria de refletir um pouco mais sobre a forma de interpretar o 
efeito desta variável, buscando avançar no conhecimento do funcionamento e da estrutura da língua, que, em última análise, constitui o principal objetivo de todos nós.

A lei do menor esforço, por exemplo, associada aqui à diminuição do esforço de produção pelo mecanismo da repetição, muitas vezes tem sido também usada na linha do princípio da quantidade: marcas redundantes são previsíveis; então, por que fazer esforço em repeti-las? Neste segundo caso, esta lei está sendo evocada para dar conta da eliminação de repetição de formas semelhantes. Servindo a dois senhores tão distintos, é possível que a referência à lei do menor esforço, assim estabelecida, não seja muito útil. É isto que se pode ver nos dois trechos de Martinet de 1962 e de 1973:

"Concordância é redundância, e ao contrário do que seria esperado, redundância resulta, como uma regra, do menor esforço: as pessoas não se importam em repetir se o esforço mental é por isto reduzido. (cf. Martinet, 1962, p.55);

[o comportamento humano obedece] à lei do menor esforço, de acordo com a qual o homem só desprende energia na medida em que esta permita atingir os objetivos que pretende". (Martinet, 1973, p.181)

Independentemente das múltiplas interpretações para a variável paralelismo, embora tenha sido possível correlacioná-las às funções da repetição especificadas pela análise do discurso, gostaria de voltar às idéias de Givón, particularmente às expressas em 1991, 5 porque temos de buscar restringir a forma de interpretar os fenômenos lingüísticos, seja qual for o fenômeno e seja qual for a corrente teórica assumida.

O princípio da iconicidade de Givón - em verdade um metaprincípio - formulado idealmente no sentido de que há na língua uma correlação não-arbitrária de um-para-um entre forma e função ${ }^{6}$ - é subdivido em outros princípios: da quantidade; da proximidade, da ordem seqüencial e da ordem linear. Retomo aqui o princípio da proximidade, por ser ele o único candidato a dar conta da variável paralelismo. Este princípio estabelece que: 
- entidades mais próximas funcional, conceptual ou cognitivamente serão colocadas mais próximas (espacial ou temporalmente) no nível da codificação;

- operadores funcionais serão colocados mais próximos (espacial ou temporalmente) da unidade conceptual para a qual forem mais relevantes, no nível da codificação;

- base cognitiva: é, em geral, cognitivamente transparente e reflete exigências de memória associativa, ativação difundida e priming.

Segundo Gorski (1994),

"Com relação à base cognitiva do princípio da proximidade, supõese que, se a ativação de um conceito desencadeia a ativação de outros conceitos estreitamente relacionados, segue-se que codificar conceitos com contigüidade temporal deve garantir processamento mais rápido devido à ação da memória associativa". (p.41-4)

Então, se a ativação de um conceito desencadeia a ativação de outros conceitos estreitamente relacionados, por que não estender a atuação deste princípio para a ativação de uma forma em função de outra forma semelhante, em grande parte das vezes idêntica e no mais das vezes se referindo a um mesmo estado de coisas?

Assim, retomando a segunda pergunta colocada na introdução deste texto - se existe algum princípio funcionalista estabelecido que subjaz ao paralelismo -, fica evidente que a teoria funcionalista, na sua formulação mais ampla ou mais restrita, ainda não prevê o mecanismo da repetição, embora ele seja usual nas línguas naturais. Mesmo ampliando a noção de significado ou de função para dar conta de representar o estado emocional do falante, as relações sociais entre falante e ouvinte, a facilidade da fala e comunicação através da condensação, abreviação, ou meios mecânicos, diferentemente do que Labov (1994) afirma, considero que os princípios funcionalistas precisam ser ampliados, se quiserem dar conta de forma cabal do mecanismo da repetição. 
Reflitamos um pouco mais: há evidências de que nem sempre o paralelismo envolve repetição mecânica das formas. Na tendência de repetição de variantes explícitas de plural, por exemplo, somente o -S plural desencadeia outro $-S$ plural. Da mesma forma, apenas o de preposicional desencadeia outro de preposicional. ${ }^{7}$ Mas, por outro lado, a harmonização vocálica - paralelismo no plano da palavra - não tem contrapartida de significado e pode ocorrer mesmo em um fenômeno de natureza morfossintática, como a expressão variável do modo imperativo, evidenciando a força da aproximação de formas semelhantes. Além disso, trabalhos variacionistas de base funcionalista estrita (Weiner \& Labov, 1981) e de base funcionalista ampla (Braga, 1986 e Schiffrin, 1981), envolvendo a variável paralelismo, e trabalhos sob a perspectiva da análise discurso, envolvendo mecanismos de repetição (Tannen, 1989), concluíram que pode haver a repetição meramente mecânica.

Segundo Tannen (1989, p.87), a neurolingüística evidencia que

"pacientes afásicos que sofreram destruição completa de áreas do cérebro [responsáveis pela] produção da linguagem e, conseqüentemente, perderam sua capacidade de produção espontânea de produção lingüística (...) retiveram a capacidade de repetir com exatidão; repetir com sombra (ou seja, repetir com demora de segundos); e repetir com transformações simples, como mudança de tempo, pessoa, e tipo de sentença. (...) Os exemplos de Whitaker de produção automática por pacientes afásicos com danos cerebrais são estreitamente similares a repetições e variações encontradas em amostras em conversação normal". ${ }^{\circ}$

Portanto, tudo leva a pressupor que existe uma contraparte cognitiva subjacente à repetição, independentemente da atitude do falante. O que o falante faz é usar brilhantemente esta capacidade, fazendo dela o melhor proveito possível, o que se reflete nas diversas funções observadas em todos os processos de repetição. A função primária da repetição evidencia-se como cognitiva: capacidade de aproximar coisas, fatos, eventos, sensações, desejos, emoções, e formas e significados lingüísticos, em função de suas semelhanças. 
Retomando novamente a primeira pergunta da introdução, considero que a variável paralelismo é indubitavelmente de natureza funcional, não por causa de sua função dentro do discurso, seja em que extensão este termo for usado, mas, sim, porque esta variável só encontra sua explicação em forças de natureza externa à língua.

Também, a terceira pergunta feita, se o paralelismo que perpassa pelos diferentes subsistemas lingüísticos pode ser interpretado através de um só princípio, só tem uma resposta: sim! - um princípio de base cognitiva que possibilita ao ser humano fazer agrupamentos, formar blocos pelas semelhanças formais, que encontra sua atuação maximizada quando atua em conjugação com a função, no sentido mais amplo que se possa atribuir a este termo.

O que subjaz à variável paralelismo, ou seja, à capacidade de repetição, subjaz também a outros aspectos do comportamento humano. O comportamento humano exibe com nitidez a produtividade ou a funcionalidade da realização de atividades em bloco, com aproximação pelas semelhanças, observado nas mais diferentes situações: na produção lingüística oral, na produção lingüística escrita, num jogo de futebol, na moda, entre outros aspectos; e, também, na própria necessidade de o ser humano formar e proteger grupos.

\section{4 - CONSIDERAÇÕES FINAIS}

Muito ainda precisa ser feito para que possamos ter respostas mais seguras para as perguntas que discutimos aqui. Mais questões se colocam; o que significa que já avançamos um pouco mais no conhecimento da realidade que nos rodeia, especialmente no que diz respeito à realidade lingüística. Alguns pontos que buscam um repensar contínuo devem nortear nossos futuros passos, quais sejam:

1) O controle do paralelismo em todas as nossas análises variacionistas. Fazendo nossas as palavras de Tannen (1989, p.87), diríamos que "a repetição é uma estratégia lingüística fundamental, forte, e infinitamente útil.” A 
(não)interferência do paralelismo no efeito de outras variáveis lingüísticas e não-lingüísticas precisa ser efetiva e continuamente testada. Definitivamente, as diversas ocorrências de uma mesma variável dependente, nas séries, não constituem um evento binomial independente e as ocorrências em série são freqüentes o suficiente até para interferirem no funcionamento de outras variáveis (cf. Scherre \& Naro, 1992), diferentemente do que colocam Sankoff \& Laberge (1978, p.119):

"(...) tem sido ainda aceita a prática de tratar sucessivas ocorrências de uma variável, mesmo no mesmo enunciado, como um experimento binomial independente. Aqueles que usam este modelo reconhecem, naturalmente, que vários tipos de relações de coocorrência podem se estabelecer entre dados vizinhos de uma variável (...). Entretanto geralmente procedemos sob esta hipótese (independência), não somente porque ela simplifica a análise, mas também porque, em termos de sua não freqüência nos dados, relações de coocorrência não afetariam seriamente os resultados dos procedimentos estatísticos para estimar os efeitos de outras restrições lingüísticas e sociolingüísticas". (grifos meus)

2) A busca do entendimento do efetivo papel do significado na repetição formal, tendo em vista a existência de resultados que ora evidenciam repetição de forma em função do significado ora repetição mecânica independentemente do significado.

\section{3) O entendimento da amplitude do fenômeno da repeti-} ção na relação tempo e espaço da produção das formas lingüísticas, buscando estabelecer uma caracterização não-arbitrária do conceito de série, tendo em vista que a variável paralelismo opera tanto na língua falada quanto na língua escrita (cf. Santos (1977). Isto também implica entender o papel dos enunciados isolados e dos primeiros de uma série, se semelhante ou se diferente, e, também, a direcionalidade da repetição: se da esquerda para a direita ou se bidirecional. 
4) A análise natural, consciente e sistemática das motivações em competição, nos termos expostos por Du Bois (1985; 1987), buscando entender como essas forças se interrelacionam, que efeitos são mais fortes e como os fenômenos se agrupam ou de distanciam em função destas forças. A inexistência de motivações em competição na língua inserida no contexto social é que seria inesperada.

5) A busca da correlação entre forças em competição e fenômenos de variação estável ou de mudança lingüística, objetivando testar as idéias de Labov (1994) e as de Naro (1996) a respeito do papel de variáveis funcionais, o que implicará precisar o lugar de cada fenômeno no ciclo funcional proposto por Givón (1979).

6) O entendimento, por um lado, da atuação de restrições que privilegiam a recuperação ou manutenção da informação e, por outro, o de restrições que conduzem à repetição formal sem levar em conta aspectos informacionais, especialmente nos fenômenos que se expressam através de variantes explícitas e de variantes zero. Já há evidências de que há zeros de comportamento diferente, mesmo na análise de um único fenômeno, subjacentes, portanto, a princípios diferentes. Na concordância de número em português, um zero ausência de uma forma presa tem comportamento diferente de um zero ausência de uma forma livre: enquanto o primeiro conduz a mais zeros, o segundo pode conduzir a mais variante explícita (cf. Scherre, 1991, p.58-61; Vazzata Dias, 1995, p.579;68-73; Naro, 1981b; Scherre \& Naro, 1991; Scherre \& Naro, 1997).

Enfim, os estudos independentes feitos pelos variacionistas e pelos analistas do discurso, evidenciando regularidades no fenômeno da repetição, enfatizam a importância deste aspecto nas línguas naturais. ${ }^{9}$ Alguns estudos variacionistas, em particular, mostram a repetição de aspectos fonológicos e morfológicos, incluindo a 
repetição de zeros, que não são salientados nos estudos clássicos de repetição feitos à luz da análise do discurso. Então, fica bastante claro que a teoria da variação, o funcionalismo e a análise do discurso podem interagir e contribuir, conjunta e harmoniosamente, para o estudo do funcionamento e da estrutura da língua.

\section{NOTAS}

${ }^{1}$ Este texto é uma versão reduzida e modificada do capítulo 7 de minha tese de doutorado. Fui estimulada por Maria Luiza Braga a apresentá-lo num encontro de funcionalistas realizado na PUC/RJ, em fevereiro de 1996. Neste encontro, participei da discussão do macro-tema Discurso e abordagens quantitativas, junto com Maria Luiza Braga, Helena Gryner e Maria da Conceição Auxiliadora de Paiva. Algumas mudanças entre a redação do capítulo 7 e a deste texto devem ser creditadas às discussões com meus pares, especialmente com Maria Luiza Braga, a quem agradeço pelo estímulo recebido. Eventuais erros de interpretação são, todavia, de minha inteira responsabilidade.

${ }^{2} \mathrm{Na}$ literatura internacional, a primeira referência a esta restrição em pesquisas variacionistas, no plano oracional, data de 1978 e foi feita por Poplack em seus estudos sobre a concordância de número no espanhol de Porto Rico (texto publicado em 1980). No plano discursivo, a primeira referência deve ser atribuída a Weiner e Labov em 1977 (texto publicado em 1983), em um estudo sobre as passivas sem agente em inglês. O efeito do paralelismo é ainda encontrado no trabalho de Schffrin (1981) sobre a alternância entre passado e presente histórico em narrativas orais no inglês; no de Sankoff e Laberge (1978) sobre a alternância entre as formas on/tu/vous, on/ils e nous/on no francês de Montreal; no de Lefebvre (1981) sobre a concordância verbal no Quechua; no de Braga (1982) sobre o deslocamento para a esquerda e topicalização no crioulo de Cabo Verde e no de Guy (1981) sobre a concordância de número no português do Brasil. Na literatura nacional, no nível discursivo e na fala de uma mesma pessoa, a primeira referência sistemática em português deve ser atribuída a Omena que, em 1978, realizou um estudo sobre as formas pronominais variantes em função acusativa. Em verdade, referências a influências desta variável, sob a denominação de efeito gatilho, especialmente na relação falante-ouvinte, são feitas, pela primeira vez, por Emmerich, no segundo semestre de 1977 (p.398), retomadas em 1984, num estudo sobre a concordância verbal de pessoa no português de contato do Alto Xingu. Referências indiretas, para desconsiderar dados da análise, são feitas 
também por Gryner, já no primeiro semestre de 1977 (p.39), num trabalho sobre a concordância com verbos impessoais. Outras referências envolvendo esta mesma variável são ainda feitas por Silva (1992) - num estudo sobre a alternância seu/dele- para a retirada de fatores de efeito categórico (comunicação pessoal). Em 1981, reflexões mais sistemáticas envolvendo a variável o paralelismo já são feitas por Macedo (1981, p.147, 165-166), ao estudar o uso do futuro do subjuntivo. Desde 1986, de forma direta ou indireta, todos os pesquisadores do Programa de Estudos Sobre o Uso da Língua (PEUL) se reportam à variável paralelismo em seus trabalhos: Braga (1986), sobre construções de tópico; Naro (1981a), sobre cancelamento do sujeito; Omena (1996), sobre alternância nós/a gente; Mollica (1989; 1991; 1995), sobre presença/ausência de de diante de que; Gryner (1990), sobre alternância modo-tempo em orações condicionais; Scherre (1988; 1991; 1997), Scherre \& Naro (1991; 1992; 1993) e Naro \& Scherre (1996), sobre concordância de número; Scherre et alii (1997), sobre a expressão do modo imperativo. A partir de 1992, um conjunto significativo de jovens pesquisadores brasileiros têm verificado sistematicamente o efeito desta variável em suas dissertações de mestrado (cf. Malvar, 1992; Felgueiras, 1993; Cunha, 1993; Fernandes, 1996; Vazzatta Dias, 1996; Lorengian, 1996; Carvalho, 1997; Costa, 1997; Santos, 1997).

3 Outros fatores como o número de sílabas do verbo, polaridade da estrutura, presença/ausência de clítico, etc. são importantes para o entendimento deste fenômeno. Focalizei aqui apenas o paralelismo, tendo em vista os objetivos do presente artigo. Nos outros fenômenos apresentados, também entram em jogo outros fatores.

${ }^{4}$ Ver, também, Johnstone (1991, p.11-35); Marcuschi (1992); e Silva (1996).

${ }^{5}$ As idéias de Givón (1991) são brilhantemente retomadas por Gorski (1994, p.3856), de quem tomamos emprestadas algumas citações.

${ }^{6}$ Se este princípio não fosse idealizado, os variacionistas nem poderiam se utilizar de princípios funcionalistas, por assumirem que, em determinados contextos, as possibilidades de escolha dizem respeito ao mesmo estado de coisas, ou seja, têm o mesmo valor de verdade ou, em outras palavras, o mesmo significado referencial. De qualquer forma, mesmo que haja nuanças de significado entre as alternativas, usa-se hoje a metodologia quantitativa, e essas nuanças são controladas através de variáveis independentes. Mesmo assim, ao se trabalhar um dado fenômeno sob a ótica da teoria da variação, sempre se está assumindo algum grau de aleatoriedade na escolha de uma ou outra variante (cf. Sankoff, 1988b). Segundo Labov (1994, p.551), "muitos argumentos funcionais são estabelecidos para explicar estruturas invariantes. Nos últimos anos, o mesmo tipo de argumento tem sido livremente aplicado a elementos variáveis da estrutura lingüística, e em particular a restrições sobre regras variáveis." 
${ }^{7}$ Mesmo isto é ainda discutível. Ressalvadas as diferenças de análise, Rangel (1994/ 1996, p.21), analisando presença/ausência de preposição em contextos queístas, concluiu que a presença de material fônico de favorece a presença da preposição de, até mais do que a própria preposição, em oposição à ausência de massa fônica idêntica, cujo efeito é desfavorecedor.

8 Todavia, Tannen (1989, p.87), mesmo considerando a importância destas pesquisas com relação ao caráter automático de estratégias de repetição, considera que "há diferenças cruciais entre o uso de estratégias de repetição por afásicos e não-afásicos no sentido de que os primeiros limitam-se à produção automática da linguagem, enquanto os últimos usam a repetição em conjugação adicional com produção deliberada da linguagem."

9 Johnstone (1994, p.176-98) apresenta uma vasta bibliografia, composta de 275 títulos, das mais diversas áreas, que abordam o mecanismo da repetição. O título mais antigo data de 1782.

${ }^{10}$ PR é o peso relativo, projetado por programas do pacote Varbrul (cf. Sankoff, 1988b; Pintzuk, 1988; Naro, 1992).

${ }^{11}$ Resultados ainda não publicados.

\section{REFERÊNCIAS BIBLIOGRÁFICAS}

BRAGA, Maria Luiza. Left-dislocation and topicalization in capeverdean creole. Ph.D. Dissertation, University of Pennsylvania, 1982.

. Construções de tópico de discurso. In: Relatório final de pesquisa: Projeto subsídios do Projeto Censo à educação. Rio de Janeiro: UFRJ, Faculdade de Letras, 1986. v.III. p.393-53, inédito.

CARVALHO, Hebe Macedo Concordância nominal: uma análise variacionista. João Pessoa: UFPA, 1997. Dissertação de Mestrado, inédito.

COSTA, Ana Lúcia dos Prazeres. A variação entre as formas do futuro e de pretérito imperfeito no português informal do Rio de Janeiro. Rio de Janeiro: UFRJ, 1997. Dissertação de Mestrado em Lingüística, inédito.

CUNHA, Cláudia de Souza. Indeterminação pronominal do sujeito. Rio de Janeiro: UFRJ, 1993. Dissertação de Mestrado em Língua Portuguesa, inédito.

DU BOIS, John W. Competing motivations. In: HAIMAN, John. Iconicity in syntax. Amsterdam: John Benjtiming, 1985, p.343-65. 
DU BOIS, John W. The discourse basis of ergativity. Language, LSA, 63(4):80555, dez. 1987.

EMMERICH, Charlotte. Um traço propulsor numa língua de contato. In: ENCONTRO NACIONAL DE LINGÜÍSTICA, 2º , Rio de Janeiro, 1977. Anais... Rio de Janeiro, PUC, 1977. p.393-9.

A lingua de contato no Alto Xingu - origem, forma e função. Rio de Janeiro: UFRJ, Faculdade de Letras, 1984, Tese de Doutorado em Lingüística, inédito.

FELGUEIRAS, Carmen Maria. Análise da variação no uso da preposição PARA. Rio de Janeiro: UFRJ, Faculdade de Letras. Dissertação de Mestrado em Lingüística, 1993, inédito.

FERNANDES, Marisa. Concordância nominal na região sul. Florianópolis: UFSC, 1996. Dissertação de Mestrado, inédito.

GIVÓN, Talmy. Syntax and semantics 12: Discourse and Syntax. New York: Academic Press, 1987.

. Functionalism and grammar - a prospectus. University of Oregon. 1991.

GORSKI, Edair Maria. O tópico semântico-discursivo na narrativa oral e escrita. Rio de Janeiro: UFRJ, Faculdade de Letras, 1994. Tese de Doutorado em Lingüística, inédito.

GRYNER, Helena. A variação de concordância com verbos impessoais na cidade de Petrópolis. Rio de Janeiro: UFRJ, Faculdade de Letras. Dissertação de Mestrado em Lingüística, 1977, inédito.

- Variação de tempo-modo e conexão nas orações condicionais em português. Rio de Janeiro: UFRJ, Faculdade de Letras, 1990. Tese de Doutorado em Lingüística, inédito.

GUY, Gregory R. Linguistic variation in Brazilian Portuguese: aspects of the phonology, syntax, and language bistory. University of Pennsylvania, 1981. Ph.D. Dissertation.

HAIMAN, John. Iconic and economic motivation. Language, LSA, 59(4):781819, dez. 1983.

JOHNSTONE, Barbara.(ed.) Repetition in discourse interdisciplinary perspectives. Norwood, New Jersey: Ablex Publishing Corporation. 1994.

KIPARSKY, Paul. Explanation in Phonology. In: PETERS, Stanley. (ed.). Goals of linguistic theory. New Jersey: Prentice Hall, 1972. p.189-225.

LABOV, William. The overestimation of functionalism. In: —- Principles of Linguistic Change. Blackwell, 1994. p.547-68. 
LEFEBVRE, Claire. Variation in plural marking: the case of Cuzco quechua. In: SANKOFF, David. \& CEDERGREN, Henrietta. (eds.). Variation Omnibus. Canada: Linguistic Research Inc., 1981. p.73-84.

LIRA, Solange de Azambuja. Nominal, pronominal and zerosubject in brazilian portuguese. University of Pennsylvania, 1982. Ph.D Dissertation.

LOREGIAN, Loremi. Concordância verbal com o pronome tu na fala do sul do Brasil. Florianópolis: UFSC, 1996. Dissertação de Mestrado, inédito.

MACEDO, Alzira Verthein Tavares de. O uso do futuro do subjuntivo em português: regularização de uma forma verbal. Rio de Janeiro: UFRJ, Faculdade de Letras, 1981. Tese de Doutorado em Lingüística, inédito.

MALVAR, Elisabete da Silva. A realização do objeto direto de terceira pessoa em cadeia anafórica. Brasília: UnB, 1992. Dissertação de Mestrado em Lingüística, inédito.

MARCUSCHI, Luíz Antônio. A repetição na lingua falada-formas e funções. Recife: 1992. Tese de Titular, inédito.

MARTINET, André. A functional view of language. $1^{\mathrm{a}}$. ed. London: Oxford University Press, 1962.

. Elementos de lingüistica geral. Lisboa: Sá da Costa, 1973.

MOLlICA, Maria Cecília de Magalhães. Queísmo e Dequeísmo em português. Rio de Janeiro: UFRJ, Faculdade de Letras, 1989. Tese de Doutorado, inédito.

Processing and morpho-semantic effects in complemantation in Brazilian Portuguese. Language Variation and Change. Cambridge University Press. 3 (1991):265-74.

(De) que falamos? Rio de Janeiro: Tempo Brasileiro, 1995.

NARO, Anthony J. Morphological constraints on subject deletion. In: SANKOFF, David \& CEDERGREN, Henrietta. (eds.). Variation Omnibus. Canada: Linguistic Research Inc., 1981a. p.351-8.

. The social and structural dimensions of a syntactic change. Language. LSA, 57(1):63-98, 1981b.

. Modelos quantitativos e tratamento estatístico. In: MOLLICA, Ma Cecília (org.) Introdução à sociolingüística variacionista. Cadernos Didáticos. FL/ UFRJ. 1992. p.17-25.

. The functional nature of variation. XXV New ways of analyzing variation. NWAVE) - Las Vegas: Universidade de Nevada, 1996, inédito.

NARO, Anthony Julius. \& VOTRE, Sebastião Josué. Emergência da sintaxe como um efeito discursivo. In: Relatório final de pesquisa: Projeto subsídios do Projeto Censo à educação. Rio de Janeiro, UFRJ, Faculdade de Letras, 1986. V.III. p.454-81, inédito. 
NARO, Anthony Julius \& SCHERRE, Maria Marta Pereira Disfluencies in the Analysis of Speech Data. Language Change and Variation and Change, Cambridge University Press. 8(1966):1-12.

OMENA, Nelize. Pronome pessoal de terceira pessoa: suas formas variantes em função acusativa. Rio de Janeiro: PUC, 1978. Dissertação de Mestrado, inédito.

- A referência à primeira pessoa do discurso no plural. In: Silva, Giselle M. de Oliveira e \& SCHERRE, Maria Marta Pereira. (orgs.) Padrões sociolingüísticos - análises de fenômenos variáveis do português falado no Rio de Janeiro. Rio de Janeiro: Tempo Brasileiro, 1996. p.183-215.

PINTZUK, Susan. VARBRUL programs. 1988, inédito.

POPLACK, Shana. The notion of the plural in Puerto Rico Spanish: competing constraints on /s/ deletion. In: LABOV, William. (eds.) Locating language in time and space. Philadelphia: University of Pennsylvania, 1980. p.55-67.

RANGEL, Márcia Pacifici. O queísmo no português atual do Brasil-uma tentativa de análise variacionista. Brasília: UnB, 1994/1996, inédito.

SANKOFF, David. Sociolinguistics and syntactic variation. In: Newmeyer, Frederick J. (Ed.) Linguistics: the Cambridge survey. Volume IV (Language: the sociocultural context). New York: Cambridge University Press, 1988a , p.141-160.

. Variable rules. In: AMMON, Ulrich; DITTMAR, Norbert \& MATTHEIER, Klauss J. (eds.) Sociolinguistics - An international handbook of the science of language and society. Berlin/New York: Walter de Gruyter, 1988b, p.984-8.

SANKOFF, David \& LABERGE, Suzanne. Statistical dependence among successive occurrences of a variation in discourse. In: SANKOFF, David. (ed.). Linguistic variation: models and methods. New York: Academic Press, 1978. p.119-26.

SANTOS, Adriana Morcelles dos Santos. O futuro verbal no português do Brasil em variação. Brasília: UnB, 1997. Dissertação de Mestrado, inédito.

SCHERRE, Maria Marta Pereira. Reanálise da concordância nominal em português. Tese de Doutorado. Rio de Janeiro: FL/UFRJ, 1988. inédito.

. A concordância de número nos predicativos e nos particípios passivos. Organon - A variação no português do Brasil. Porto Alegre, UFRGS-Instituto de Letras, 18(1991):52-70.

Variação da concordância nominal no português do Brasil: influência das variáveis posição, classe gramatical e marcas precedentes. Colóquio Internacional Substandard und Sprachwandel im brasilianischen Portugiesich/Substandard e mudança lingüistica no português brasileiro. Berlim, Instituto Ibero-Americano, 1997, inédito.

SCHERRE, Maria Marta Pereira \& NARO, Anthony Julius. Marking in Discourse: Birds of a Feather. Linguistic Variation and change. 3(1991): 23-32. Cambridge University Press. 
SCHERRE, Maria Marta Pereira \& NARO, Anthony Julius. The serial effect on internal and external variables. Language Variation and Change. Cambridge University Press. 4(1992):1-13.

. Duas dimensões do paralelismo verbal no português popular do Brasil. Delta. São Paulo, 9(1993):1-14.

A concordância de número no português do Brasil: um caso típico de variação inerente. In: Hora, Dermeval da (org.) Diversidade lingüistica no Brasil. João Pessoa: Idéia, 1997. p.93-114.

SCHERRE et alii. Phonic parallelism: evidence from the imperative in Brazilian Portuguese. XXVI New ways of analyzing variation (NWAVE) - Universidade de Laval/Quebec, 1997, inédito.

SCHIFFRIN, Deborah. Tense variation in narrative. Language, LSA, 57(1):5-62, mar, 1981.

SILVA, Denise Elena Garcia da. La oralidad en el discurso narrativo escrito de adolescentes mexicanos: el fenomeno lingüístico da la Repeticion. México, D.F.: Universidade Nacional Autônoma do México, 1996. Tese de Doutorado em Lingüística Hispânica.

SILVA, Giselle Machline de O. e. Estudos da regularidade na variação dos possessivos no português do Rio de Janeiro. Rio de Janeiro: UFRJ, Faculdade de Letras, 1982. Tese de Doutorado em Lingüística, inédito.

TANNEN, Deborah. Talking voices: repetition, dialogue, and imagery in conversational discourse. Cambridge: Cambridge University Press, 1989.

VAZZATTA DIAS, Juçá Fialho. A concordância de número nos predicativos e nos particípios passivos na fala da região sul: um estudo variacionista. Florianópolis: UFSC, 1995. Dissertação de Mestrado, inédito.

WEINER, E. Judith \& LABOV, William. Constraints on the agentless passive. In: Journal of Linguistics, 19(1983):29-58. 